\title{
1. Experimental analysis of debris distribution of masonry panels subjected to long duration blast loading
}

${ }^{a}$ Advanced Structural Engineering Research, Infrastructure Group, Faculty of Engineering and the Environment, Highfield Campus, University of Southampton, Southampton, UK, SO17 1BJ

\section{Abstract}

Blast loading of structures is a complex system dependent on a vast number of parameters from both the structure and blast wave. Even for the simplest of structures, small changes to its size and shape can have a large effect on the result when subjected to blast; additionally, small changes to the pressure or duration of the blast wave can drastically alter its interaction with a specific structure. This paper, as part of a larger in-depth research study, investigates the breakage patterns and debris distribution of masonry panels subjected to blast loads with a positive phase duration typically exceeding $100 \mathrm{~ms}$. Three experimental trials were conducted, in which ten masonry panels of varying geometries were subjected to blast loads with peak static overpressures of approximately $55 \mathrm{kPa}$ and $110 \mathrm{kPa}$, with corresponding positive phase durations of $200 \mathrm{~ms}$ and $150 \mathrm{~ms}$ respectively. All structures underwent total structural failure, followed by significant debris distribution with the results showing structural geometry, blast overpressure and impulse to be the key parameters responsible for the breakage pattern, initial fragmentation and debris distribution respectively. Keywords: long duration blast, masonry, debris distribution, breakage

\section{Introduction}

Blast and its interaction with structures is a complex system. According to Needham [1], the positive phase of a blast wave is usually characterised by overpressure and is defined as the time between shock arrival and the beginning of the negative phase of the overpressure. Integrating the overpressure with the phase duration gives the impulse transmitted by the blast wave, thus a large positive phase duration or high pressure will lead to a high transmitted impulse. Long duration blast is defined here as a blast wave with a positive phase duration in excess of $100 \mathrm{~ms}$, producing high impulsive loading at farther stand-off distances. Examples of such explosive events include the 1981 'Mill Race trial' [2] and the 1983 'Direct Course trial'

${ }^{*}$ Corresponding Author: Tel. +44 (0) 2380592862

Email addresses: r.keys@soton.ac.uk (Richard A. Keys), s.k.clubley@soton.ac.uk (Simon K. Clubley) 
[3] in which 544 and 600 tonnes of ANFO were detonated respectively. Whilst such explosive events are unlikely to occur in urban environments, hydrocarbon vapour cloud detonations are capable of producing similar blast conditions and can occur at chemical storage or processing plants located within urban areas. Such examples include the 2005 'Buncfield Disaster' [4] with a predicted TNT equivalence of approximately 250 tonnes, or the 2013 'West Texas Fertilizer Disaster' [5] in which a fire lead to the combustion of 30 tonnes of ammonium nitrate, amongst other combustible materials.

Damage predictions are often made using pressure impulse $(P-I)$ diagrams, as displayed in Figure 1 , in which the iso-damage curves represent particular levels of damage. Whilst the multiple curves provide insight into the state of the structure and the level of damage, they offer little to no information regarding the extent of the resulting debris distribution.

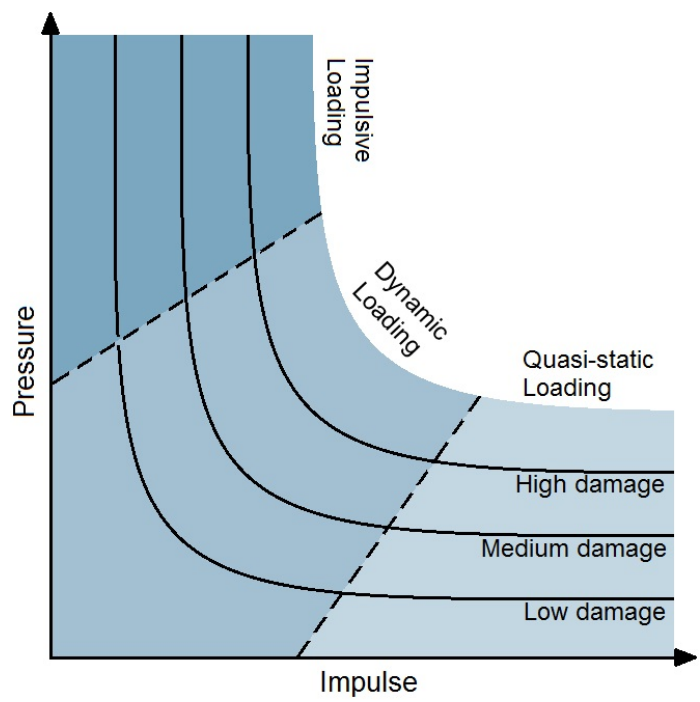

Figure 1: Representation of a $P-I$ diagram with ISO damage curves

Much research has been conducted investigating the effects of blast loading on masonry, with primary focus on the failure mechanisms of masonry [6], [7], [8]. Many results from such research greatly improve the predictive capability of iso-damage curves, through both numerical and experimental results [9], [10]. Research investigating the flight paths, impact, bounce and roll of masonry debris has also been conducted, in which the final position of individual fragments are statistically predicted using source terms based on the initial conditions [11], [12]. Almost all research conducted into masonry structures and their response subject to blast loading has focused on small to medium sized charges at relatively close ranges, or in some cases, near field detonations [13]. Such detonations produce extremely high pressure blast waves, resulting in high levels of damage; however the duration of such blast events is small, rarely exceeding 50ms. Blast waves 
with high enough pressure to cause fragmentation and long positive phase durations continue to transfer large amounts of energy post-breakage, resulting in substantial debris distributions, especially in the case of drag targets [14].

In the event of petro-chemical, or other large detonations in urban environments, the fragments from buildings constructed from brittle materials, such as concrete and masonry, produce a substantial debris distribution. This poses the threat of secondary damage to other structures, large scale infrastructure blockage and potentially lethal injuries. A long term goal of this research is to develop a fast running predictive model to assess the blockage of vital infrastructure and other potential damage caused by the effects of a long duration blast to one or more masonry structures. To achieve this, a combination of experimental and numerical data will assess the debris distribution produced by a wide variety of masonry geometries for various blast parameters. As an initial step, this paper analyses a set of key experimental trials which were conducted to assess the breakage and debris distribution of ten masonry structures when subjected to long duration blast loads.

\section{Experiments}

Three experimental trials, accommodating a total of ten test items, were conducted at the Air Blast Tunnel (ABT), shown in Figure 2, which is located at MoD Shoeburyness on Foulness Island in the UK. The ABT is a large shock tube designed to replicate large explosive events, with two sections for instrumentation which are $4.9 \mathrm{~m}$ and $10.2 \mathrm{~m}$ in diameter [15]. The ABT is also fitted with a rarefaction wave eliminator (RWE) at its exhaust to reduce unwanted reflections and complex airflow interfering with the test items. Previous trials conducted at the ABT show the maximum achievable peak static overpressure in the $4.9 \mathrm{~m}$ and $10.2 \mathrm{~m}$ sections to be $100-120 \mathrm{kPa}$ and $50-60 \mathrm{kPa}$ respectively with corresponding positive phase durations of approximately $200 \mathrm{~ms}$ and $150 \mathrm{~ms}$ [16]. Using the Kingery and Bulmash polynomials for hemispherical surface charges [17], the TNT equivalence of the blast wave was approximately 450 Tonnes at a stand-off distance of $250 \mathrm{~m}$ in the $4.9 \mathrm{~m}$ section and 200 Tonnes at $250 \mathrm{~m}$ in the $10.2 \mathrm{~m}$ section.

With the experimental trials being the first step in a larger research project, the test items are constructed from the simplest form of masonry, single leaf running bonds. Each test item was constructed using frogged facing London bricks, with a mass of $\approx 2.1 \mathrm{~kg}$, dimensions of $210 \mathrm{~mm} \times 100 \mathrm{~mm} \times 65 \mathrm{~mm}$ and a maximum compressive strength of approximately $4-6 \mathrm{Nmm}^{-2}$. The bricks were joined by a class (ii) mortar

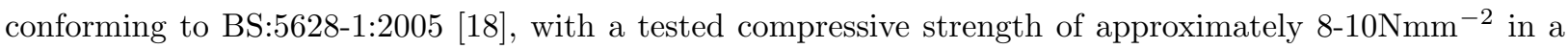
$10 \mathrm{~mm}$ bedding. Each test item was constrained at a vertical height of $2 \mathrm{~m}$ corresponding to 26 layers of 


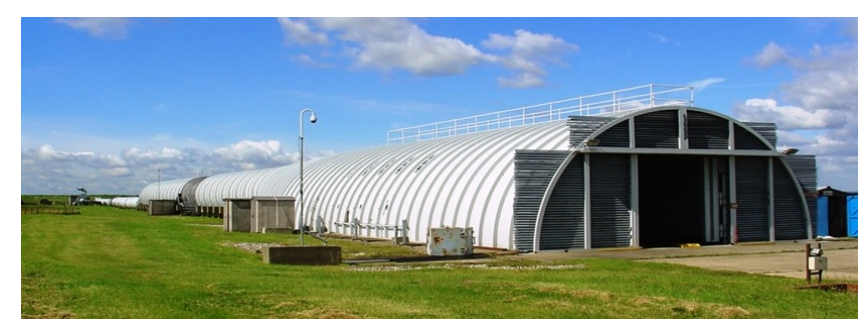

Figure 2: The Air Blast Tunnel (ABT)

bricks with the base mortared to the ground; this arrangement follows the same design as previous high explosive masonry tests conducted by Keys and Clubley [19].

The primary objective of the experiments was to achieve a set of baseline results which can be used to develop damage predictions for three dimensional masonry structures. To achieve this, two categories of test items were defined; the first category employs simple geometries which represent small panels in a potential structure with the smallest panel being $1 \mathrm{~m}$ wide. As the simple geometries involved corner panels, boundary conditions applied to the outer edges would not necessarily be consistent between structures. Therefore, for comparative purposes, the simple geometries were implemented without boundary conditions. The second category uses half rectangular structures enclosed by a steel housing designed to reduce any infill effects of the blast wave from above. The purpose of these structures is to draw comparisons between the simple base panels in isolation and as part of a larger structure without the complication of infill before breakage. To ensure there was as little infill as possible without physically connecting the masonry to the steel roof, the top layer of masonry was covered with vinyl strips, to which a layer of expanding foam was applied. This method closed the gap between the masonry and the steel, reducing any hammer effects from the roof as well as restricting the blast in-fill. This method ensures there was as little restraint on the masonry from above as reasonably possible within the confines of the ABT.

For each structure, every $1 \mathrm{~m}$ panel was painted a different colour to allow comparisons between individual sections and every brick was assigned a unique number. To aid the post trial debris collection, $0.5 \mathrm{~m} \times 0.5 \mathrm{~m}$ grids were marked on the ground in the $10.2 \mathrm{~m}$ section; the $4.9 \mathrm{~m}$ section however does not allow for two dimensional debris collection and so the pre-existing radial $1 \mathrm{~m}$ bin markers were used. Both the $10.2 \mathrm{~m}$ and $4.9 \mathrm{~m}$ sections were instrumented with Endveco-8510 and Kulite-20D pressure transducers to monitor the static and dynamic pressures respectively. Kulite-LQ125 pressure transducers are also mounted on rigid steel surfaces to monitor reflected pressure. Each test item was recorded by two or more high speed phantom cameras mounted in protective steel cases, each recording at 2000fps. Each test item is listed in table 1 
Table 1: ABT 'BWL' series summary table

\begin{tabular}{|c|c|c|c|c|c|c|c|c|}
\hline \multirow{2}{*}{ SID } & \multirow{2}{*}{ Enclosed } & \multirow{2}{*}{$\begin{array}{l}\text { Dimensions } \\
(x, y, z)(\mathrm{m})\end{array}$} & \multirow{2}{*}{$\begin{array}{c}\text { Target } \\
p_{i}(\mathrm{kPa})\end{array}$} & \multicolumn{5}{|c|}{ Recorded } \\
\hline & & & & $p_{i}(\mathrm{kPa})$ & $I$ (kPa.ms) & $p_{r}(\mathrm{kPa})$ & $q(\mathrm{kPa})$ & $t^{+}(\mathrm{ms})$ \\
\hline BWL1A & - & $0.1 \times 1 \times 2$ & 110 & 100 & 7260 & 290 & 42 & $214 \pm 2$ \\
\hline BWL1B & - & $1 \times 2 \times 2$ & 55 & 60 & 3220 & 129 & 24 & $150 \pm 2$ \\
\hline BWL1C & $\checkmark$ & $4 \times 2 \times 2$ & 55 & 59 & 3423 & 129 & 23 & $168 \pm 2$ \\
\hline BWL2A & - & $1 \times 1 \times 2$ & 110 & 108 & 7187 & 322 & 59 & $218 \pm 2$ \\
\hline BWL2B & - & $0.1 \times 1 \times 2$ & 55 & 59 & 3164 & 131 & 24 & $160 \pm 2$ \\
\hline BWL2C & - & $1 \times 1 \times 2$ & 55 & 60 & 3952 & 131 & 24 & $179 \pm 2$ \\
\hline BWL2D & $\checkmark$ & $3 \times 1.5 \times 2$ & 54 & 60 & 3304 & 131 & 24 & $164 \pm 2$ \\
\hline BLW3A & - & $1 \times 1 \times 2$ & 110 & 112 & 7011 & 320 & 55 & $219 \pm 2$ \\
\hline BWL3B & - & $0.1 \times 2 \times 2$ & 55 & 57 & 3362 & 124 & 24 & $152 \pm 2$ \\
\hline BWL3C & $\checkmark$ & $3 \times 2 \times 2$ & 55 & 57 & 3365 & 124 & 21 & $160 \pm 2$ \\
\hline
\end{tabular}

along with its unique Structure ID (SID), dimensions, target overpressure and peak recorded values from the closest pressure gauge. The positive phase durations quoted in Table 1 were obtained by comparing the time of arival with the time at which $p_{i}$ dropped below $0 \mathrm{kPa}$. The values were rounded to the nearest milisecond giving an uncertainty of $\pm 2 \mathrm{~ms}$.

Figures 3, 4 and 5 display plan schematic drawings of the first, second and third trials respectively for detailed reference, indicating the position of each structure with accompanying photographs and SID, positions and orientations of the phantom cameras and the position of each instrumentation arrray.

\section{Results \& Analysis}

The pressure time histories displayed in Figures 3, 4 and 5 show that for the $10.2 \mathrm{~m}$ section of the ABT, gauges $\mathrm{p}_{i} 3, \mathrm{p}_{i} 4$ and $\mathrm{p}_{i} 5$ recorded consistently higher peak pressures than gauges $\mathrm{p}_{i} 1$ and $\mathrm{p}_{i} 2$. The duration of these peak pressures are between $2-8 \mathrm{~ms}$ and each reading appears after the arrival of the wave front, indicating that they result from reflections off of the steel enclosure. Gauges $\mathrm{p}_{i} 1$ and $\mathrm{p}_{i} 2$, located on the outer edge of the ABT, were positioned alongside each structure and thus did not record any reflections. Discarding the reflections, the mean recorded peak incident overpressure in the center of the $10.2 \mathrm{~m}$ section of the ABT across all three trials was $55 \mathrm{kPa}$, with all values falling within $\pm 3 \mathrm{kPa}$ of the mean and a range of $5 \mathrm{kPa}$. The mean recorded peak incident overpressure at the edges of the $10.2 \mathrm{~m}$ section of the ABT across all three trials was $58 \mathrm{kPa}$, with all values falling to within $\pm 2 \mathrm{kPa}$ of the mean and a range of $3 \mathrm{kPa}$. The overall mean recorded peak incident overpressure in the $10.2 \mathrm{~m}$ section of the ABT across all three trials was $56 \mathrm{kPa}$, with all values falling to within $\pm 4 \mathrm{kPa}$ of the mean and a range of $7 \mathrm{kPa}$. The only incident pressure gauge in the $4.9 \mathrm{~m}$ section of the tunnel was $\mathrm{p}_{i} 6$, which was positioned upstream from the test items, also 


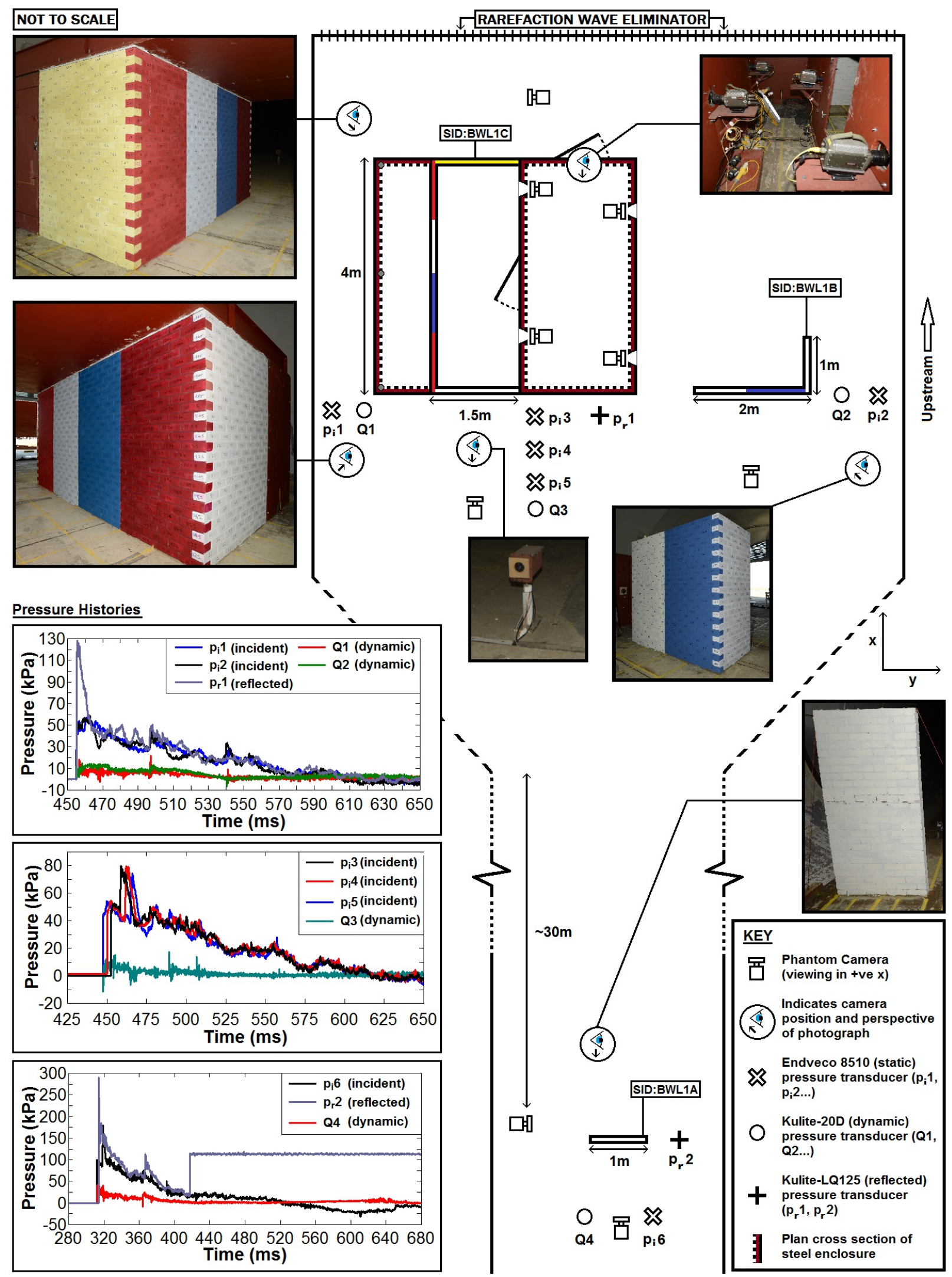

Figure 3: Plan view of ABT trial 'BWL1.' Full schematic detaling the positioning of each test item accompanied by pre-trial photographs, gauge locations and their corresponding pressure time histories with phantom camera positioning. 


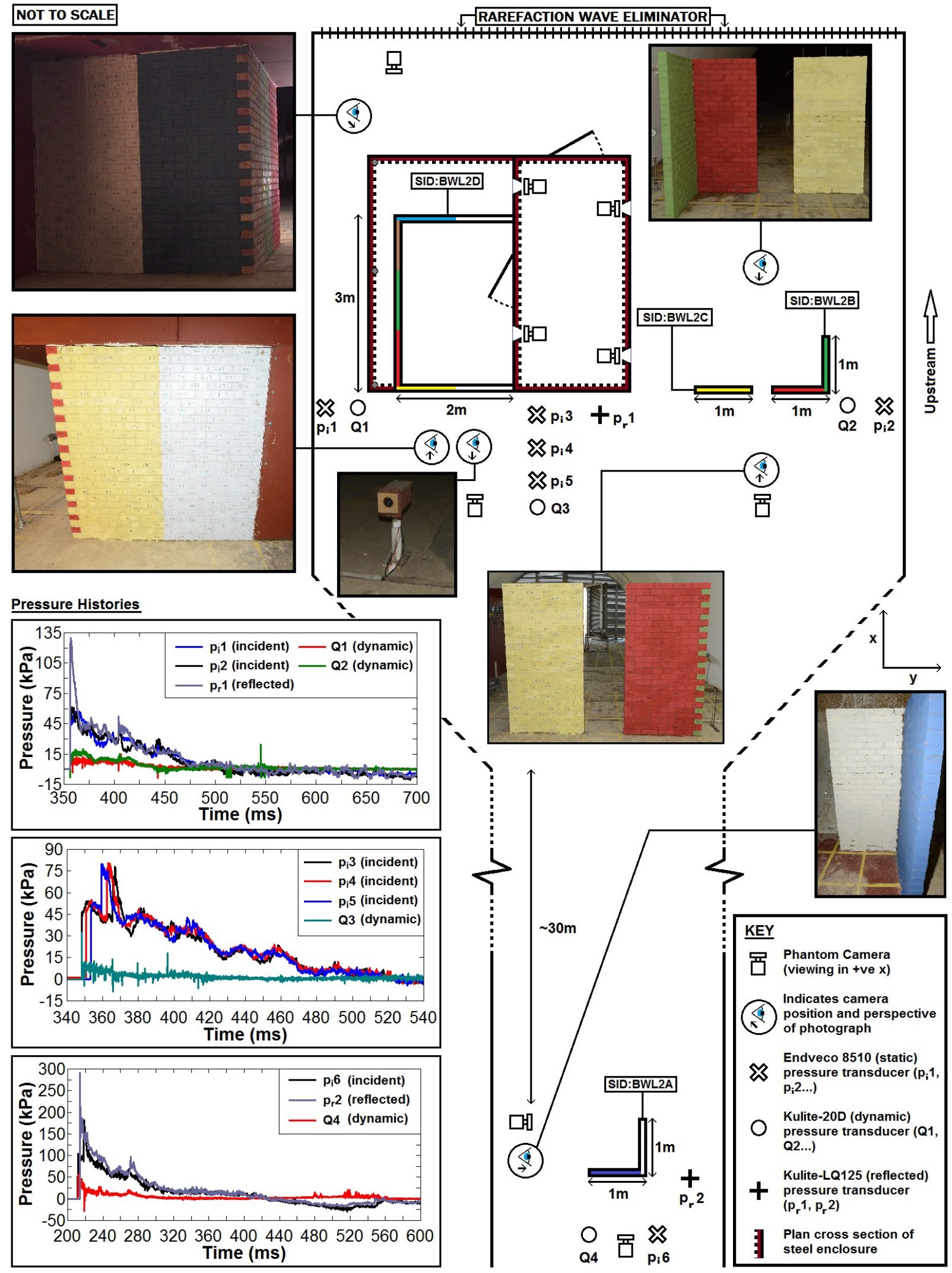

Figure 4: Plan view of ABT trial 'BWL2.' Full schematic detafling the positioning of each test item accompanied by pre-trial photographs, gauge locations and their corresponding pressure time histories with phantom camera positioning. 


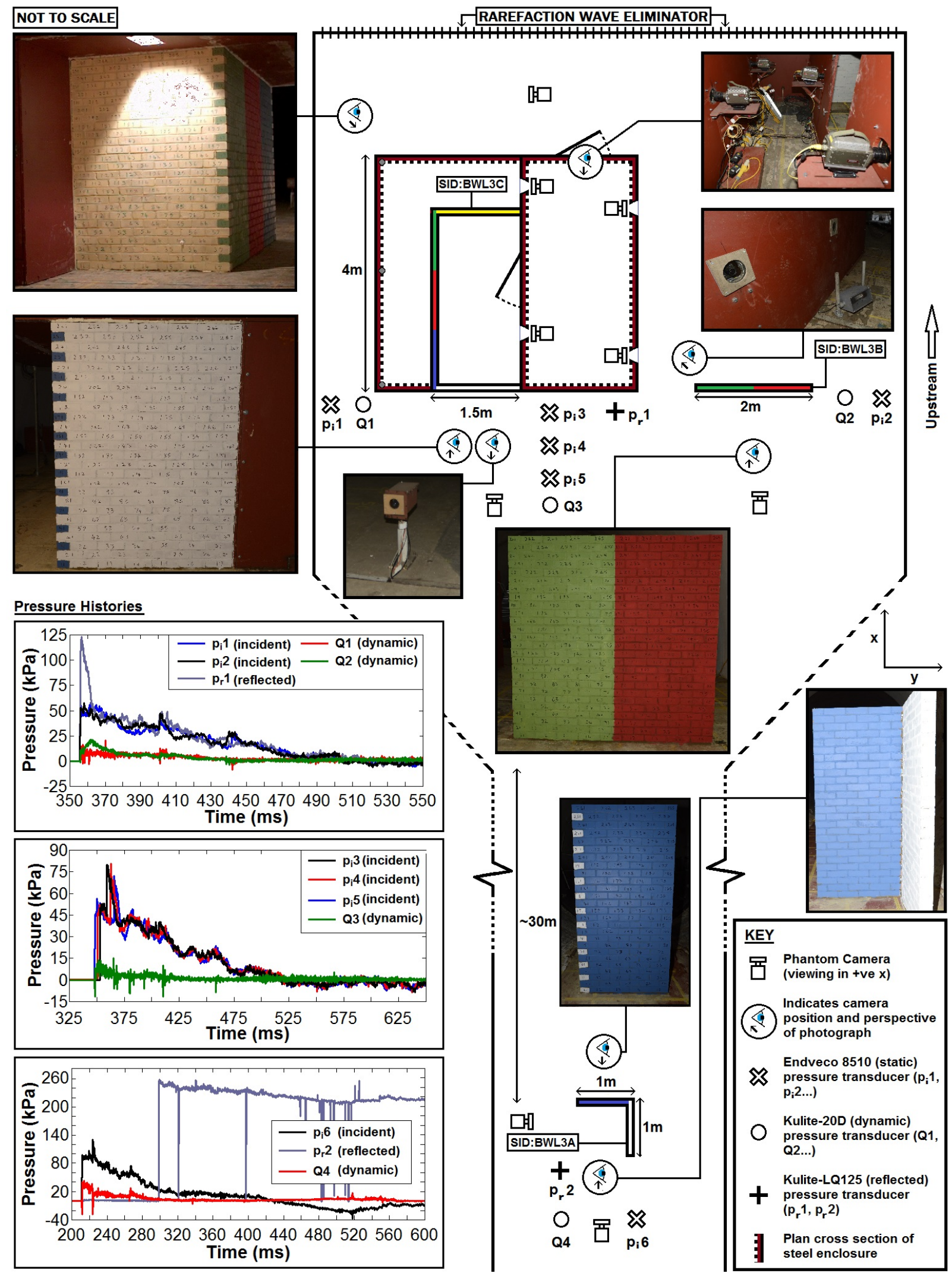

Figure 5: Plan view of ABT trial 'BWL3.' Full schematic detrling the positioning of each test item accompanied by pre-trial photographs, gauge locations and their corresponding pressure time histories with phantom camera positioning. 
recorded small reflections from the test items. Once again, discarding the reflections, the recorded peak incident overpressures in the $4.9 \mathrm{~m}$ section of the $\mathrm{ABT}$ were $100 \mathrm{kPa}, 108 \mathrm{kPa}$ and $112 \mathrm{kPa}$ for trials 1,2 and 3 respectively, giving an average peak incident overpressure of $107 \mathrm{kPa}$ across all three trials. The recorded $p_{i}$ values displayed in Table 1 show the recorded peak incident overpressures disregarding any reflections. Overall, the incident overpressures were achieved to within $0-8 \%$ of the target value in the $10.2 \mathrm{~m}$ section and $2-9 \%$ of the target value in the $4.9 \mathrm{~m}$ section.

\subsection{Breakage patterns and failure mechanisms}

Figures 6 and 7 show the breakage at 50ms and 200ms respectively for each structure located in the $4.9 \mathrm{~m}$ section of the ABT. The first visual signs of crack formation occurred between $10 \mathrm{~ms}$ and $15 \mathrm{~ms}$ and led to clear separation and fragmentation by $50 \mathrm{~ms}$. The positive phase in the $4.9 \mathrm{~m}$ section of the ABT was approximately $200 \mathrm{~ms}$ by which point each structure was entrained in the blast wave. The arrows shown in Figure 6 highlight the initial crack lines responsible for the breakage pattern.

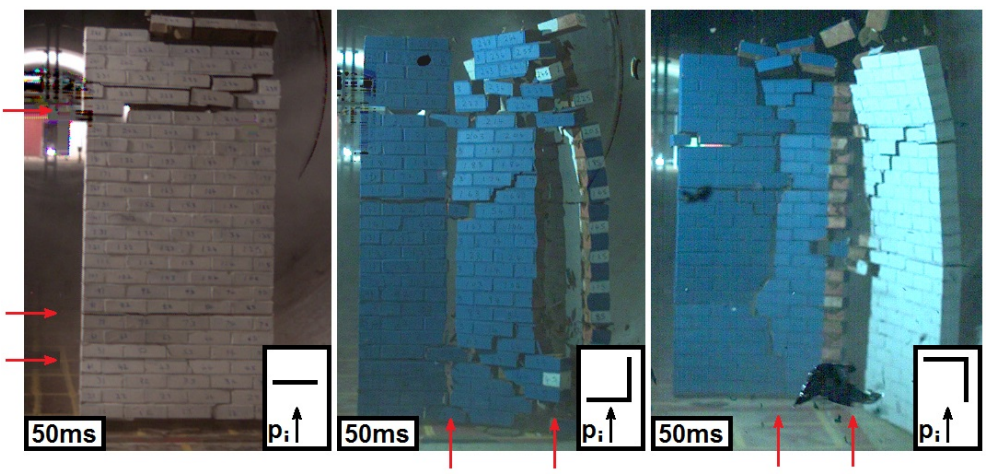

Figure 6: Breakage at 50ms (left to right: BWL1A, BWL2A, BWL3A)

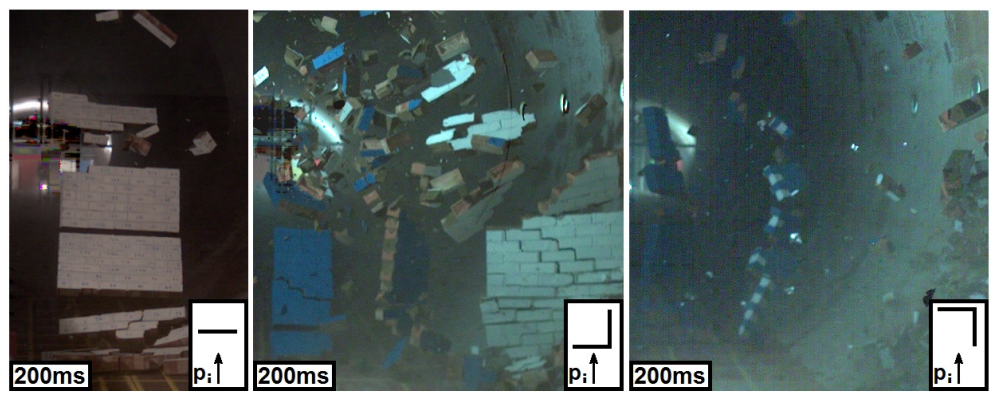

Figure 7: Breakage at 200ms (left to right: BWL1A, BWL2A, BWL3A)

The crack formation observed in structure BWL1A at 50ms are horizontal fracture lines running the 
width of the structure along bedding planes at approximately $0.3 \mathrm{~m}, 0.5 \mathrm{~m}$ and $1.6 \mathrm{~m}$ from the base of the structure. At $200 \mathrm{~ms}$, more horizontal breakage lines were present with smaller fragments appearing at the top and bottom of the structure. The BWL1A test is a repeat of a pervious trial conducted by Keys and Clubley [20], which demonstrated an almost identical breakage pattern. Both BWL2A and BWL3A developed vertical cracks due to the added support of the corner geometry which increased resistance to horizontal cracking. In both cases, vertical cracks form down the centre of the structure and along the corner joint which leads to rotation of the side panel about the connection, causing a larger number of initial fragments. In the case of BWL2A, the side panel did not develop any visible crack lines until the front panel was completely separated; however both the front and side panel of BWL3A begin to fail in unison. Figure 7 shows the panels normal to the blast become entrained in the blast wave by $200 \mathrm{~ms}$, with the corner structures both showing higher levels of initial fragmentation. The side panels of BWL2A and BWL3A are forced outwards, perpendicular to the blast wave with slight rotation from BWL3A and significantly higher rotation in BWL2A due to its initial breakage pattern.

Figures 8, 9 and 10 show the breakage at 50ms and 150ms of structures BWL1B, BWL2B\&C and BWL3B respectively. These are the unenclosed, smaller structures located in the $10.2 \mathrm{~m}$ section of the ABT, which recorded peak incident overpressures of $55-65 \mathrm{kPa}$ with a positive phase of approximately $150 \mathrm{~ms}$.

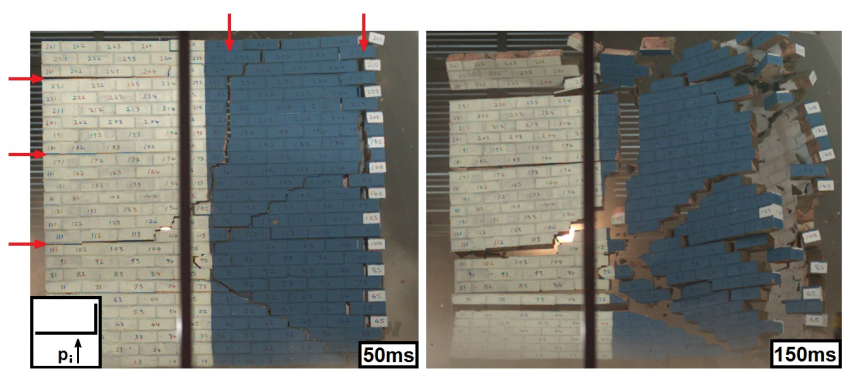

Figure 8: Breakage at 50ms (left) and 150ms (right) of BWL1B

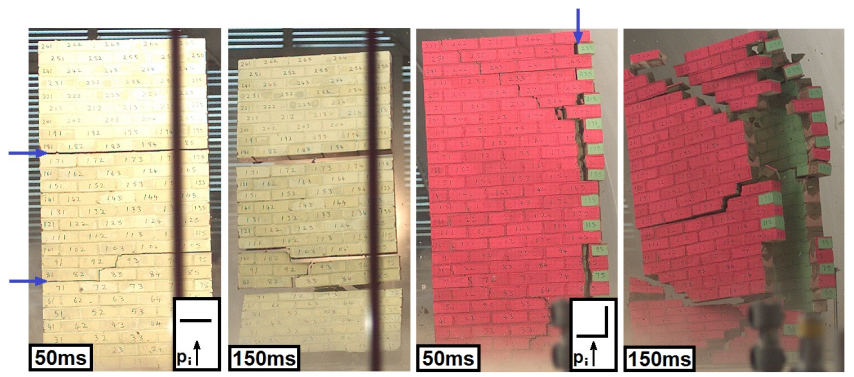

Figure 9: Breakage of (left to right) BWL2C 50ms, BWL2C 150ms, BWL2B 50ms, BWL2B 150ms 


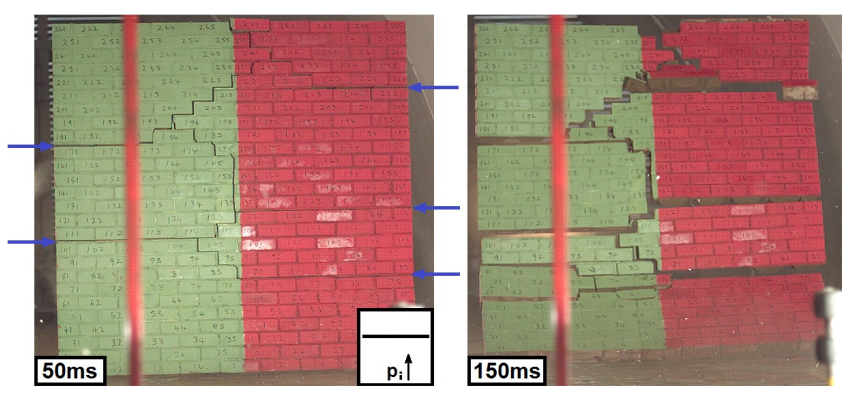

Figure 10: Breakage at 50ms (left) and 150ms (right) of BWL3B

The geometry of BWL1B provides a combination of added support from the corner joint and weakness due to the larger surface area on the exposed front panel. The initial breakage pattern observed at $50 \mathrm{~ms}$ displayed in Figure 8 shows a combination of horizontal and vertical crack lines across the exposed front panel, all of which form along bedding planes. The first cracks to form were along the corner joint, caused by the pressure across the front face which created a rotational force about the corner connection, this was followed shortly $(\approx 5 \mathrm{~ms})$ by the detachement of the upper left quadrant. Finally, additional cracking formed in the lower right quadrant of the structure resulting from the rotational force at the joint. The side panel exhibited minimal cracking at 50ms with only small, stepped cracks forming at the top and bottom of the structure near the joint. At $150 \mathrm{~ms}$, the initial crack patterns caused separation, resulting in both large fragments and additional cracking, which in turn leads to a larger number of smaller fragments. Each $1 \mathrm{~m}$ section of the structure became completely separated with the front panel split in half along the colour boundary and the side panel forced outwards with some additional rotation.

The structures BWL2C and BWL2B, shown in Figure 9, have the same geometry as structures BWL1A and BWL2A respectively but are located in the $10.2 \mathrm{~m}$ section and thus subjected to a lower incident pressure. Similar to BWL1A, at 50ms BWL2C exhibits horizontal cracking along the bedding planes at approximately $0.5 \mathrm{~m}$ and $1.5 \mathrm{~m}$ from the base of the structure; the crack line at $0.5 \mathrm{~m}$ however forms across 3 bedding planes. By $150 \mathrm{~ms}$ the lower crack extends above and below the central stepped crack resulting in the structure breaking into 5 distinct fragments. The corner structure, BWL2B, also exhibited similar breakage to its counterpart, BWL2A, with major cracking forming around the joint at 50ms; the exposed front panel however showed only minor crack lines at the top and bottom of the structure and the side panel remains completely intact. Additional horizontal cracking forms across the exposed front panel and by $150 \mathrm{~ms}$ leads to separation into a small number of large fragments. The side panel remains mostly intact with one horizontal crack forming at approximately $1.2 \mathrm{~m}$ above the base of the structure breaking the panel 
into two large fragments; as with BWL1B and BWL2A, the side panel is forced outwards towards the wall of the ABT with a rotational motion about the joint.

BWL3B, a 2m wide flat panel shown in Figure 10, forms a number of horizontal and stepped crack lines along mortar bedding planes. Horizontal cracking is expected as the linear bedding planes are the weakest parts of the structure; however as the exposed surface area is symmetric and larger than other structures tested, a larger number of vertical and stepped crack lines are formed due to drag effects around the structure. Once the initial cracks have formed and initial fragmentation has occurred, few additional cracks are observed at the end of the positive phase at 150ms. The overall breakage mechanism was similar to a combination of the $2 \mathrm{~m}$ wide front panel of BWL1B and the single front panel of BWL2C, with vertical and stepped cracks form along the centre of the face causing separation along its central axis and 2-3 horizontal cracks forming at similar intervals.

Breakage of the large enclosed structures in the $10.2 \mathrm{~m}$ section of the ABT was recorded using four phantom cameras. Two cameras were positioned in the steel enclosure capturing the breakage from the inside of the structure, one was positioned upstream capturing the breakage of the front panel and one was positioned downstream capturing the breakage of the rear panel; however, the images from the rear cameras were unclear due to dust build up obscuring the camera view. Figures 11, 12 and 13 show the breakage of structures BWL1C, BWL2D and BWL3C respectively at both 50ms and 150ms from the upstream and interior perspectives.
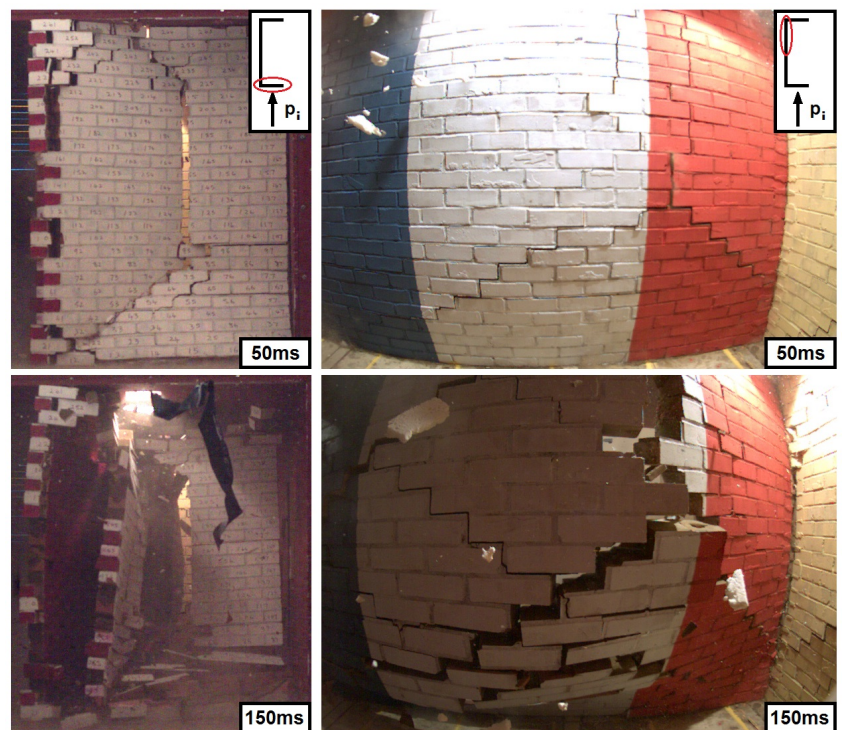

Figure 11: Breakage at 50ms (top) and 150ms (bottom) of BLW1C 


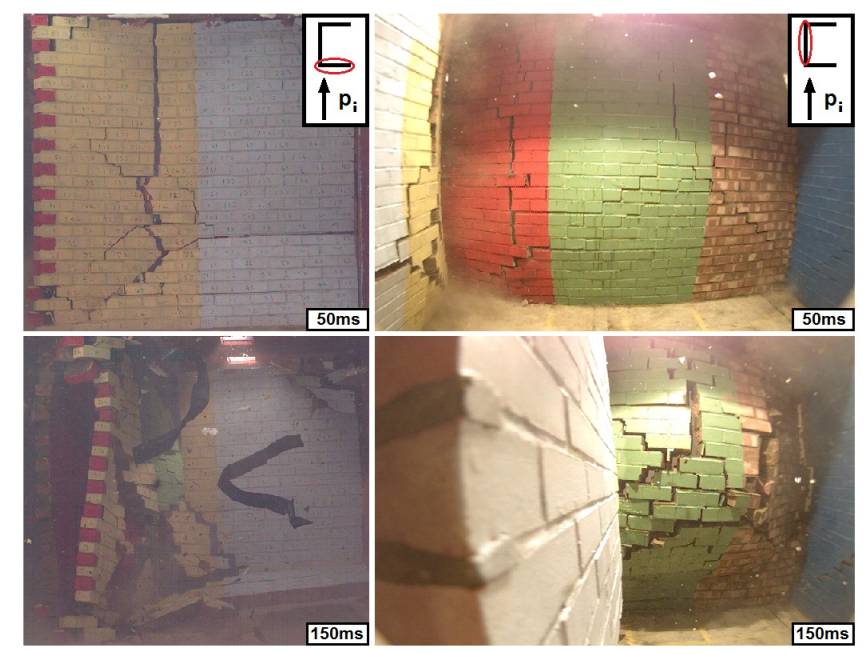

Figure 12: Breakage at 50ms (top) and 150ms (bottom) of BLW2D

Each of the large structures comprise half rectangular geometries which differ only in length and width, with measurements of $4 \mathrm{~m} \times 1.5 \mathrm{~m}, 3 \mathrm{~m} \times 2 \mathrm{~m}$ and $3 \mathrm{~m} \times 1.5 \mathrm{~m}$ for BWL1C, BWL2D and BWL3C respectively. These small changes in geometry appeared to have little effect on the overall breakage mechanisms as the camera footage shows almost identical breakage patterns at both $50 \mathrm{~ms}$ and $150 \mathrm{~ms}$ on all sides of the structures. At $50 \mathrm{~ms}$, the front panels all develop three cracks which meet at a central point. A stepped crack from the base of the corner joint, rises to join a vertical crack running to the top of the structure and a horizontal crack running to the right edge, where it meets with the steel enclosure. For all three structures, the vertical crack appears between $0.8 \mathrm{~m}$ and $1 \mathrm{~m}$ from the corner joint, despite the front panel of BWL2D being $0.5 \mathrm{~m}$ wider. The positioning of the horizontal crack line also appears consistently at approximately $0.7 \mathrm{~m}$ above the base for all three structures. For each structure, a vertical crack also appears at the corner joint which spans the height of the structure. With similar crack patterns forming across the front of three structures, the resulting failure mechanisms also show high degrees of similarity. At 150ms, the initial crack patterns across the front panel of each structure cause separation into three main fragemts. The lower fragment tilts about its base and falls inwards, the fragment initially connected to the side panel rotates about the vertical crack along the corner joint and falls inwards and the final panel is forced inwards with a higher velocity and little rotation. Small differences between the number and size of additional small fragments are observed, but the overall failure mechanism of the front panel is the same in each case.

The initial breakage pattern at $50 \mathrm{~ms}$ across the side panels are also consistent across all three structures, despite BWL1C being an additional 1m in length. In each case, stepped cracks begin to form at base of the 


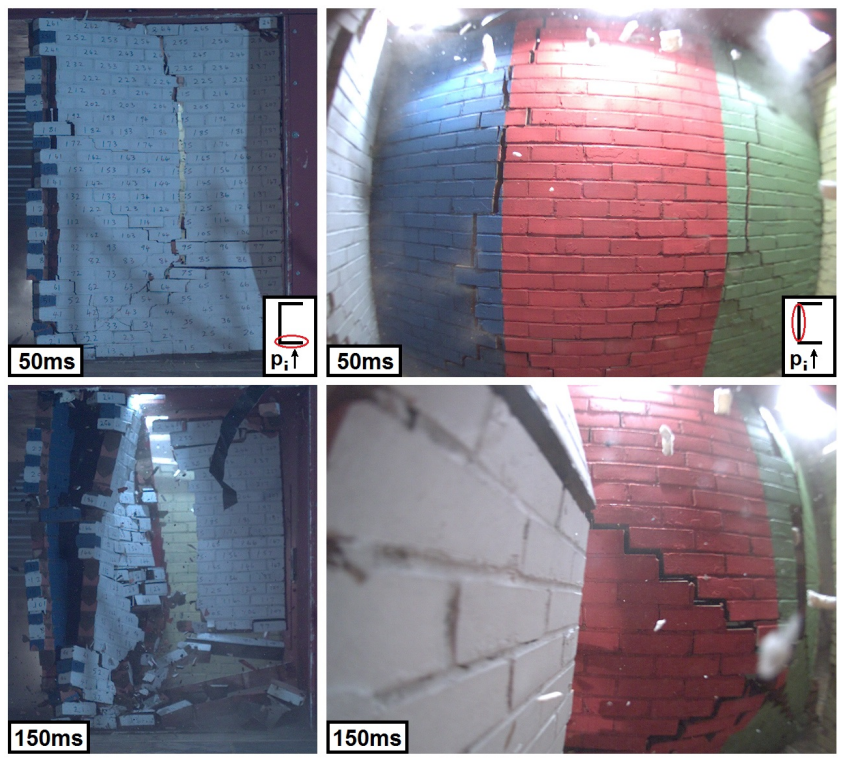

Figure 13: Breakage at 50ms (top) and 150ms (bottom) of BLW3C

corner joint which connects the rear and side panels. For each structure, the rising stepped crack reaches the $11^{\text {th }}$ row of bricks, approximately $0.8 \mathrm{~m}$ above the ground, at roughly $1 \mathrm{~m}$ from the connection to the rear panel where it intersects with a vertical crack running to the top of the structure and another stepped crack which runs to the base of the structure, approximately $2 \mathrm{~m}$ from the connection to the rear panel. For each structure, a vertical crack which spans the height of the structure appears at $1 \mathrm{~m}$ from the corner joint connecting the front and side panels. For BWL1C and BWL3C, this vertical crack intersects stepped crack at the base of the structure; however as BWL2D is an additional $1 \mathrm{~m}$ in length there is no intersection. By $150 \mathrm{~ms}$, the side panel is forced inwards primarily around the intersection of the three cracks $1 \mathrm{~m}$ from the rear panel. A large fragment is created by the vertical crack $1 \mathrm{~m}$ from the front panel and the corner joint connecting the front and side panels; rotation about the corner joint causes this fragment to fall outwards.

\subsection{Debris distribution}

To obtain an in depth analysis of the debris distributions produced by each structure, every fragment was collected and logged by mass, $x-y$ position, material type and where applicable, brick colour and number. The higher pressures and impulses observed in the $4.9 \mathrm{~m}$ section of the ABT resulted in much larger longitudinal debris distributions; however, due to its relatively small circular cross section, lateral displacement could not be logged. Figures 14, 15 and 16 show the longitudinal debris distributions, geometric identifier and debris statistics for structures BWL1A, BWL2A and BWL3A respectively, where the number of remaining whole 
bricks is shown as a percentage of the initial number of bricks, $m_{f}(\max )$ is the mass of the largest recorded fragment, $\Sigma m\left(m_{f}>0.1 \mathrm{~kg}\right)$ is the total mass of all recorded fragments above $0.1 \mathrm{~kg}$ and $\Sigma m\left(m_{f} \leq 0.1 \mathrm{~kg}\right)$ is the total mass of all recorded fragments less than or equal to $0.1 \mathrm{~kg}$. For all distributions, $x=0$ refers to the point of the structure closest to the blast, i.e. in the most upstream position.

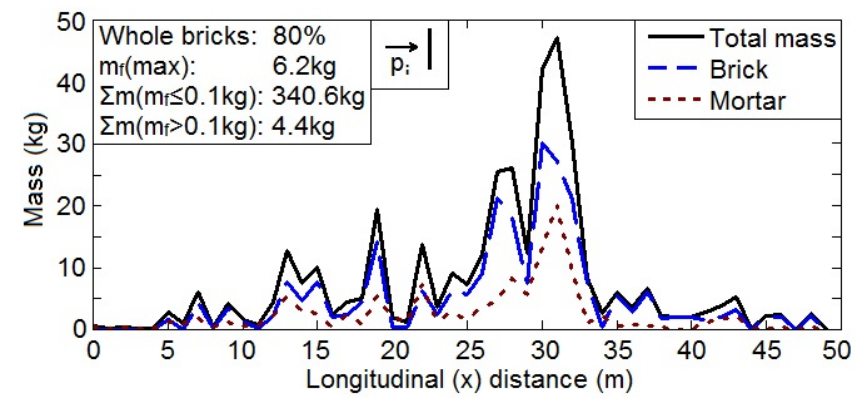

Figure 14: Longitudinal debris distribution, geometric identifier and debris statistics of BWL1A

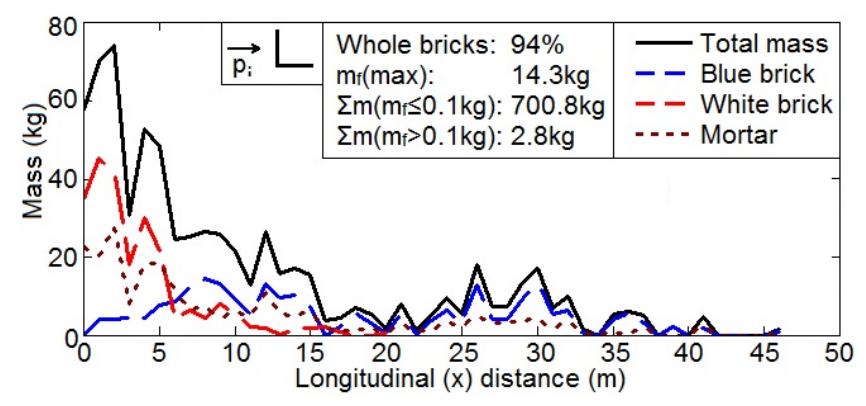

Figure 15: Longitudinal debris distribution, geometric identifier and debris statistics of BWL2A

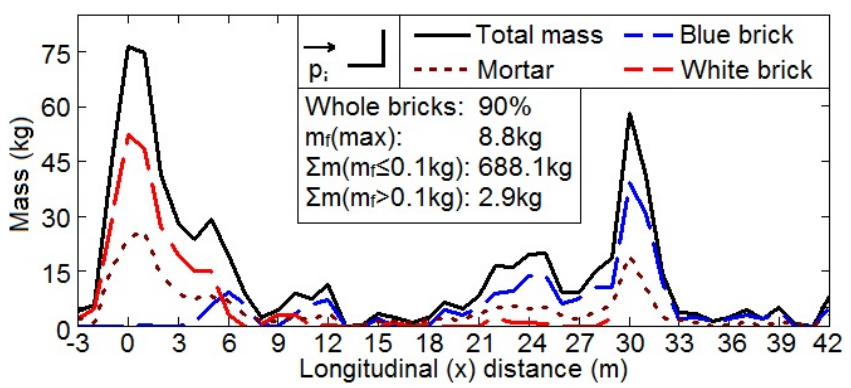

Figure 16: Longitudinal debris distribution, geometric identifier and debris statistics of BWL3A

The debris distribution of structure BWL1A, shown in Figure 14, shows a series of small peaks between $10-25 \mathrm{~m}$ followed by a large peak of approximately $45 \mathrm{~kg}$ at $30 \mathrm{~m}$. The large peak at $30 \mathrm{~m}$ is due to two instrumentation columns which partially obstruct the end of the $4.9 \mathrm{~m}$ section, thus causing some debris 
piling. In the absence of these columns, a more uniform distribution is predicted between $30-50 \mathrm{~m}$ with the maximum throw distance to be between $50-60 \mathrm{~m}$. The overall shape of the debris distribution can however be attributed to the initial crack formation and breakage pattern, with each peak corresponding to one of the initial large fragments. Approximately $80 \%$ of the bricks collected remained intact, the majority of which were found attached to varying quantities of mortar. The largest recorded fragment, with a mass of $6.2 \mathrm{~kg}$, was found at the $15 \mathrm{~m}$ mark and consisted of two whole bricks mortared together, originating from the base of the structure.

The overall shape of the debris distribution of BWL2A, displayed in Figure 15, shows approximately $70 \%$ of the debris landed within $15 \mathrm{~m}$. This result is as expected with the white bricks, which constitute the side panel, landing within the first $5 \mathrm{~m}$ upon impact with the wall of the ABT. The blue bricks, constituting the front panel, follow a relatively even distribution between $0-35 \mathrm{~m}$ with a small peak of approximately $20 \mathrm{~kg}$ at $25 \mathrm{~m}$ and another of relatively equal magnitude coinciding with the instrumentation columns at $30 \mathrm{~m}$. Approximately $94 \%$ of all bricks remained intact with the largest recorded fragment, with a mass of $14.3 \mathrm{~kg}$, found at $3 \mathrm{~m}$. The fragment consisted of 5 white bricks originating approximately $1 \mathrm{~m}$ from the base of the side panel, close to the corner joint.

The geometry of structure BWL3A can be considered a $180^{\circ}$ rotation of BWL2A with the panel normal to the blast located at the rear of the side panel. The debris distribution of structure BWL3A, displayed in Figure 16, shows the distribution of the white bricks, which constitute the side panel, to be very similar to that of BWL2A, the majority of which were located in the first $5 \mathrm{~m}$. The distribution of the blue bricks differs however, with the majority located between $20-33 \mathrm{~m}$. Approximately $45 \mathrm{~kg}$ of blue bricks were located at the instrumentation columns at 30m suggesting a larger distribution between $35-50 \mathrm{~m}$ in their absence. Similar to BWL2A, $90 \%$ of the bricks were found intact, with the largest fragment being $8.8 \mathrm{~kg}$. This fragment consisted of 3 whole blue bricks originating from the base of the blue panel normal to the blast.

Figures 17, 18, 19 and 16 show the longitudinal, lateral and $x-y$ debris distributions, geometric identifier and debris statistics for structures BWL1B, BWL2B, BWL2C and BWL3A respectively, where the number of remaining whole bricks is shown as a percentage of the initial number of bricks, $m_{f}(\max )$ is the mass of the largest recorded fragment, $\Sigma m\left(m_{f} 0.1 \mathrm{~kg}\right)$ is the total mass of all recorded fragments above $0.1 \mathrm{~kg}$ and $\Sigma m\left(m_{f} \leq 0.1 \mathrm{~kg}\right)$ is the total mass of all recorded fragments less than or equal to $0.1 \mathrm{~kg}$. For all distributions the origin, $(x, y)=(0,0)$, refers to the centre of the front panel.

The $x-y$ distribution of structure BWL1B, displayed in Figure 17, is cropped to show areas of high mass density. The highest density areas were located at $(x, y)=(1,2)$ followed by $(7,-1)$. Comparison of the 


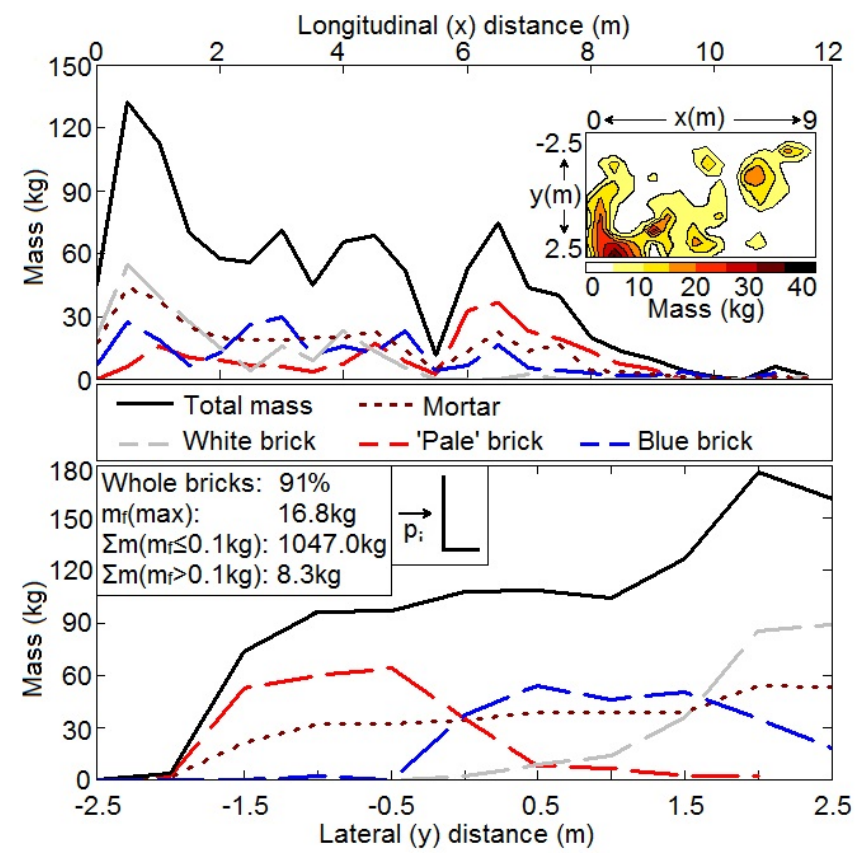

Figure 17: Longitudinal, lateral and $x-y$ debris distribution, geometric identifier and debris statistics of BWL1B

longitudinal and lateral debris distributions show the area of highest density at $(1,2)$, was caused by the white bricks which constituted the side panel, which, after becoming detached from the rest of the structure, collapsed against the wall of the ABT. The second peak at $(7,-1)$, is caused by the debris colliding with a set of lights which were used for the high speed photography. The lateral distribution shows both halves of the front panel, constructed from 'pale' and blue bricks, to comprise relatively similar distributions, with the exception of slightly more piling around the lighting at $7 \mathrm{~m}$ for the 'pale' bricks. The lateral distributions remain unaffected by the lighting and shows an even debris distribution for both panels. The debris itself consisted of mostly large fragments, the largest of which had a mass of $16.6 \mathrm{~kg}$ and was located in the high density regoin at $(1,2)$. The fragment was constructed of white bricks from the base of the side panel, on its outside edge. $91 \%$ of all bricks collected remained intact with less than $1 \%$ of the debris pile consisting of small fragments less than $0.1 \mathrm{~kg}$.

Similarly to BWL1B, the green, side panel of BWL2B became detached and collapsed against the wall of the ABT, leaving an area of high density at $(1,1.5)$, displayed in Figure 18. The longitudinal distribution shows the majority of the mass to have fallen within $5 \mathrm{~m}$ of the origin with a maximum throw distance of $11 \mathrm{~m}$. The lateral distribution shows the red bricks from the front panel did not follow a symmetrical distribution with over $80 \%$ of the mass falling towards the wall of the ABT. This was caused by the rotation 


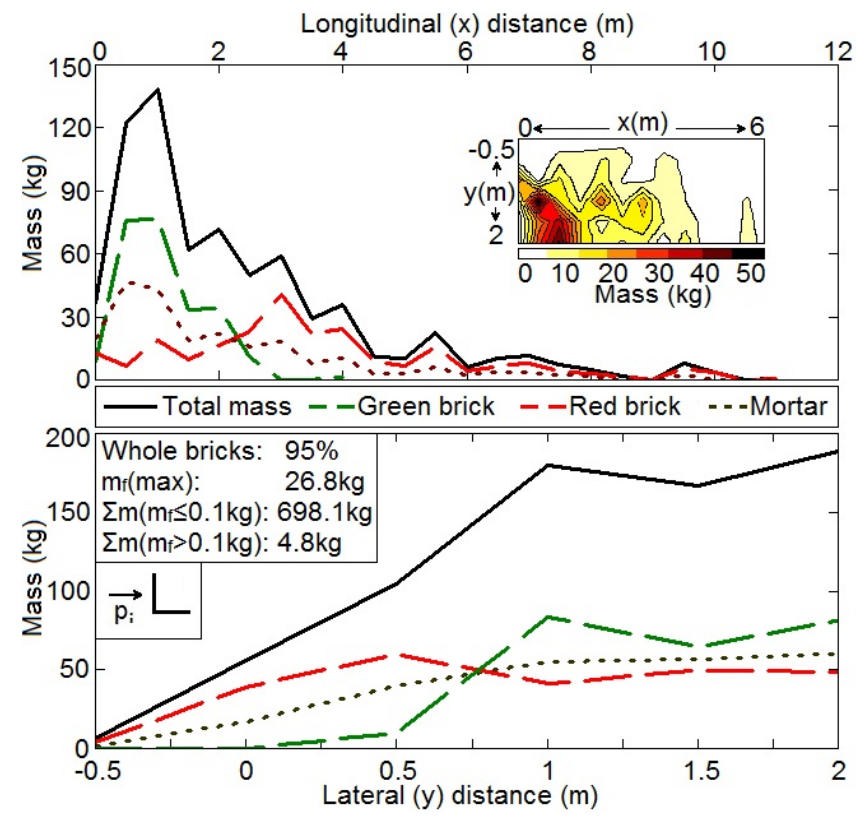

Figure 18: Longitudinal, lateral and $x-y$ debris distribution, geometric identifier and debris statistics of BWL2B

of the red panel which caused separation with the side panel. Over $95 \%$ of the bricks remained intact and many large fragments were found in the debris pile, 8 of which had a mass exceeding $10 \mathrm{~kg}$ and the three largest fragments had masses of $23.4 \mathrm{~kg}, 24.7 \mathrm{~kg}$ and $26.7 \mathrm{~kg}$. The largest fragment was located at $(0.5,1)$ and consisted of 6 red bricks and 2 green bricks from the base of the corner joint. The other two large fragments were located in the high density area surrounding $(1,1.5)$ and were both made up from green bricks originating middle and the top of the side panel.

The $x-y$ debris distribution of structure BWL2C, displayed in Figure 19, shows two regions of high density, located at $(5,0)$ and $(7,0)$ with magnitudes of approximately $50 \mathrm{~kg}$ and $75 \mathrm{~kg}$ respectively, the latter resulting from the lighting obstruction. The initial breakage, caused by horizontal crack formation, segmented the structure into 4 distinct, large fragments with the peak at $(5,0)$ being caused by the impact of the lowest fragment with the ground. The lateral distribution is symmetric about the origin for both the individual brick and mortar distributions. The largest fragment with a mass of $26.0 \mathrm{~kg}$ was located in the first high density region at $(5,0)$ and was constructed of 10 bricks originating from the lower outside edge of the structure. In the absence of the lighting obstruction, the overall longitudinal distribution is expected to have a larger maximum throw distance with the high density region at $7 \mathrm{~m}$ to be distributed between $6-12 \mathrm{~m}$.

BWL3B shared a very similar debris distribution, both longitudinally and laterally to that of BWL2C. The longitudinal distribution, displayed in Figure 20, shows even distributions of both red and green bricks. 


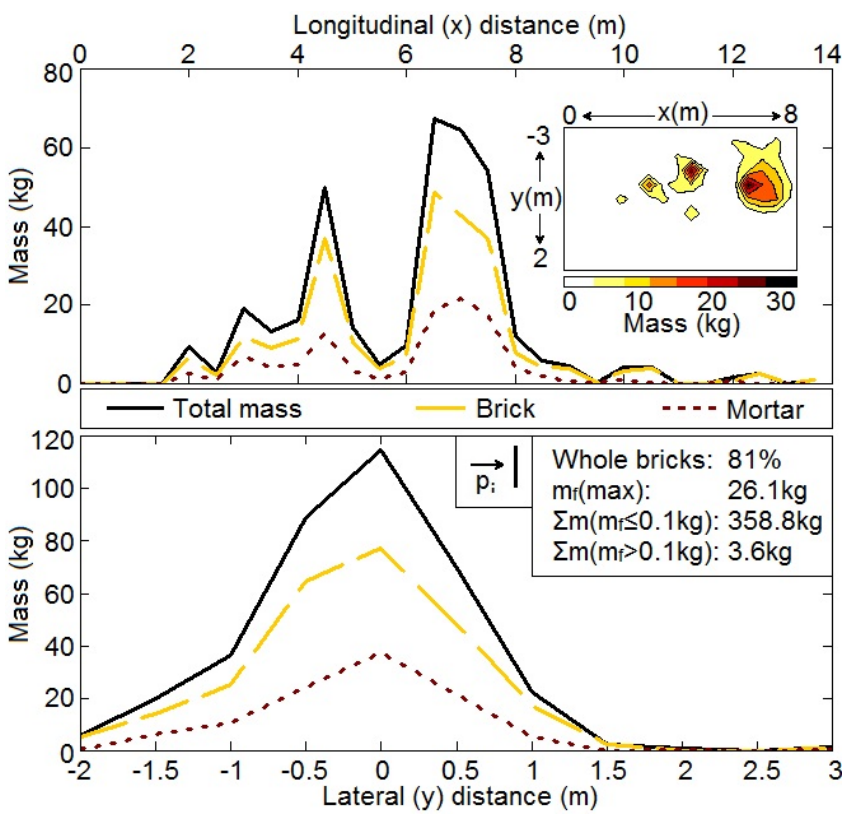

Figure 19: Longitudinal, lateral and $x-y$ debris distribution, geometric identifier and debris statistics of BWL2C

Three distinct peaks were observed of approximately $95 \mathrm{~kg}$ at $1 \mathrm{~m}$, followed by $60 \mathrm{~kg}$ at $4 \mathrm{~m}$ and $95 \mathrm{~kg}$ at $7 \mathrm{~m}$. The first two peaks were caused by the initial breakage pattern, specifically large fragments from the lower section of the structure and the final peak at $7 \mathrm{~m}$ was again caused by impact with the lighting array. Similarly to BWL2C, in the absence of the lighting, the peak at $7 \mathrm{~m}$ is predicted to be distributed between 6-12m. The lateral distribution shows both symmetrical distributions of the individual red and green panels and thus the corresponding overall lateral distribution. The largest fragment recorded from any of the unenclosed structures, with a mass of $27.5 \mathrm{~kg}$, was located at $(0.5,0.5)$ and consisted of 6 red bricks and 3 green bricks, originating from the centre of the base of the structure.

Due to extremely high density debris distribution of the large enclosed structures, accurately collecting and measuring the debris was not readily possible; furthermore, safety issues due to the unstable nature of the debris made any manual measurements both impractical and dangerous. The large enclosed structures were recorded safely with extensive photography and are displayed in Figures 21, 22 and 23, which show the debris distributions of BWL1C, BWL2D and BWL3C respectively, accompanied by an outline sketch of the debris pile which indicates the original position of the structure.

The debris distribution of BWL1C, displayed in Figure 21, shows the rear and rear side panels constrained between the floor and the roof of the steel enclosure. This shows the enclosure has successfully stopped blast infill from above as it clears the structure, meaning the rear panel is only exposed to the wrap around 


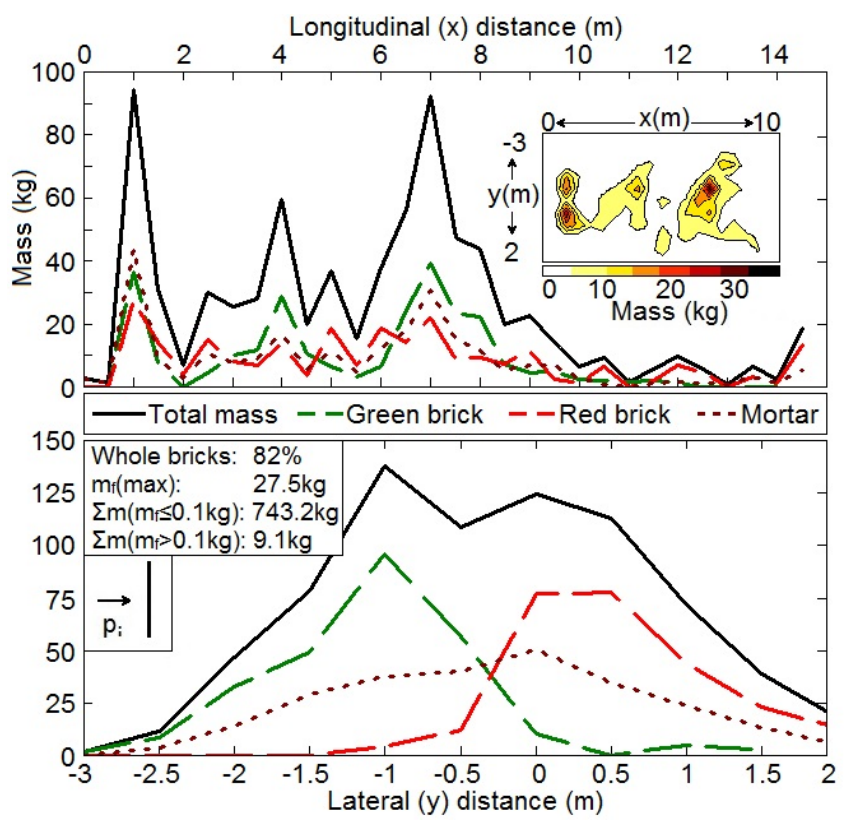

Figure 20: Longitudinal, lateral and $x-y$ debris distribution, geometric identifier and debris statistics of BWL3B

pressure from the opposing direction. The incident pressure acting on the side and rear of the structure force both panels inwards, creating a rotational motion about the corner joint, wedging the rear panel in place. Blocked by the rear panel, the debris produced by the front panel collects against the rear panel and the steel container, forming the highest point of the debris pile at approximately $1 \mathrm{~m}$ high. The base of this high density area is formed by white and red bricks from the rear side panels which are covered by white bricks from the front panel. Once the front panel is breached, the infill effect of the blast forces the front, red section of the side wall outwards, resulting in the additional $2 \mathrm{~m}$ lateral distribution. The total area covered by the debris was approximately $10 \mathrm{~m}^{2}$.

Covering approximately $12.5 \mathrm{~m}^{2}$, structure BWL2D produced a similar debris distribution and is displayed in Figure 22. As with BWL1C, the rear panel is constrained against the roof of the steel enclosure; however, there was increased breakage to the rear panel, resulting in $0.5 \mathrm{~m}$ of the rear panel closest to the steel enclosure to become detached and collapse. The rear panel of BWL2D was much more delicately wedged in place with a large number of lose bricks hanging from the edge of the structure. The front and rear panels of BWL2D were $2 \mathrm{~m}$ across, $0.5 \mathrm{~m}$ wider than the other two enclosed structures giving it a larger, weaker cross section; once the front panel was breached, a larger volume of compressed air entered the structure, resulting in a higher pressure acting on the inside of the front section of the side wall, causing a larger lateral distribution. Most of the debris was located at the rear of the structure reaching approximately $0.6 \mathrm{~m}$ high 


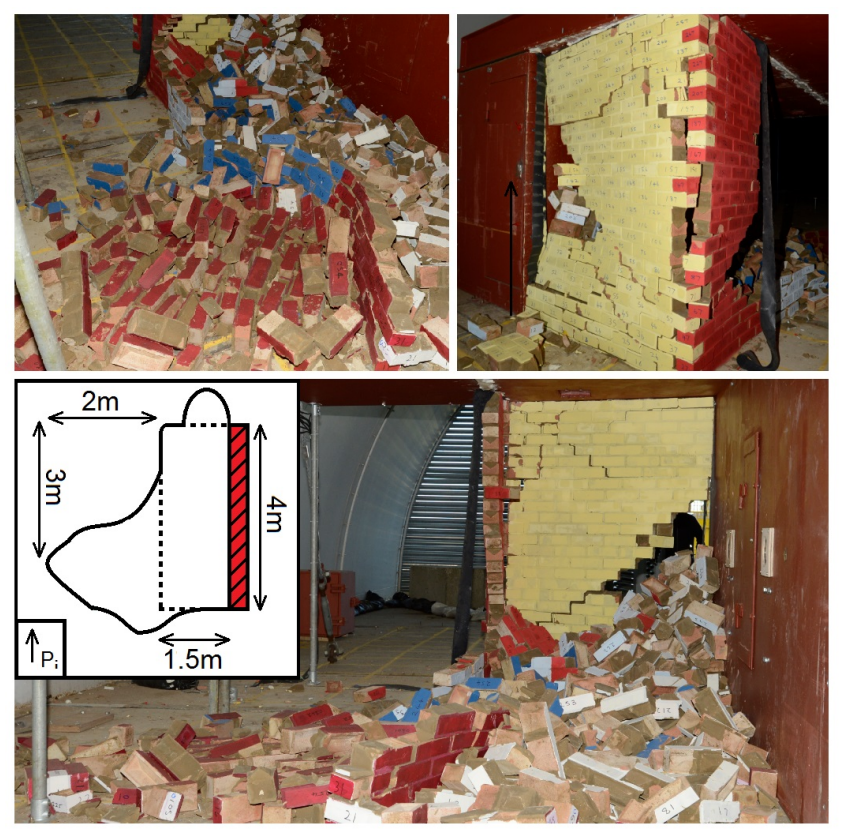

Figure 21: Debris distribution of structure BWL1C

anc panels.

The smallest of the three enclosed structures, BWL3C, produced the largest debris pile covering an approximate area of $16 \mathrm{~m}^{2}$, shown in Figure 23. Unlike the other two enclosed structures, the rear wall was not restricted by the roof of the steel enclosure. This followed as a result of the front panel impacting the rear, significantly weakening the lower half of the rear wall and causing it to collapse. The increased rotational force on the rear corner joint, resulting from the collapse of the rear panel, caused the rear, green side panel to become delicately wedged against the roof of the steel enclosure. The white bricks, originating from the front panel, were evenly spread across the interior at the bottom of the debris pile. Towards the rear, the yellow bricks from the rear wall cover the white bricks, forming the top layer of the debris pile with a peak height of approximately $0.6 \mathrm{~m}$. The red bricks from the centre panel of the side wall cover the white bricks in the middle section of the interior, with the blue bricks from the front of the side wall forming the entire lateral distribution at the front of the structure.

\section{Conclusions}

Initial comparisons of all test items show a number of similarities in terms of both breakage and debris distribution. Structures BWL1A and BWL2C, which both share the same 1m wide geometry, both form 

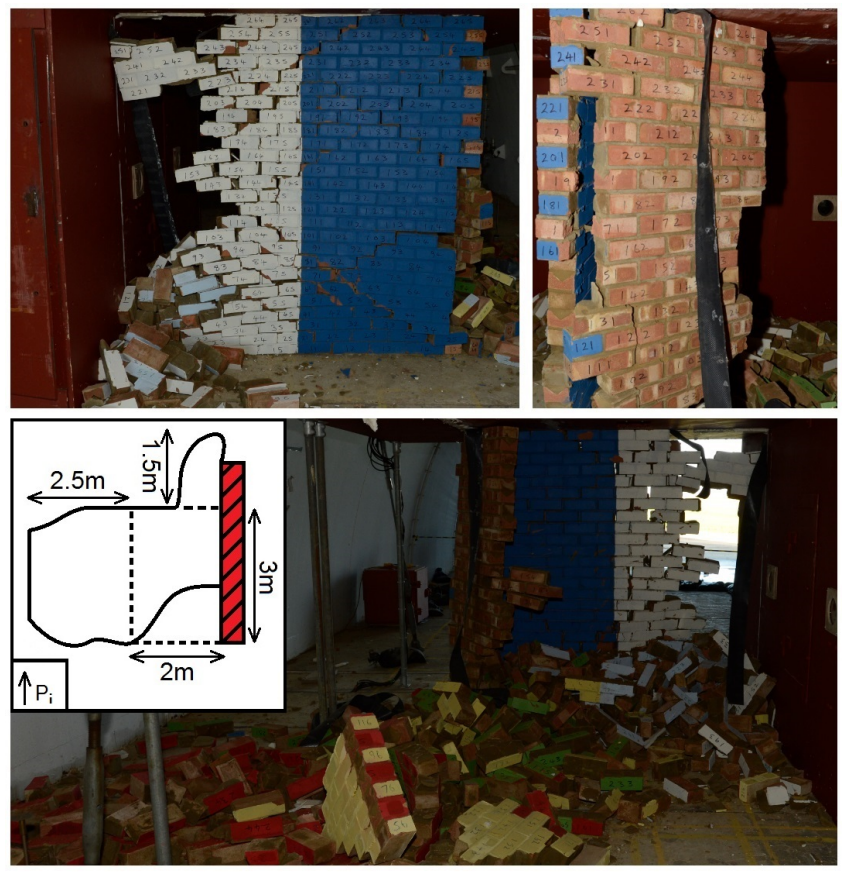

Figure 22: Debris distribution of structure BWL2D

the same set of horizontal cracks by $50 \mathrm{~ms}$; however BWL1C, which was subjected to $110 \mathrm{kPa}$ displayed a much larger number of initial fragments. Previous experiments conducted by Keys and Clubley [19] which subjected the same $1 \mathrm{~m}$ wide panel to a $110 \mathrm{kPa}$ for $10 \mathrm{~ms}$ also showed the same initial breakage patterns after $10 \mathrm{~ms}$, that is, there were two horizontal cracks forming on the lower sections of the structure. For the long duration case, additional crack formation and fragmentation continues until 50-100ms. This suggests that the whilst the peak pressure is responsible for the initial breakage, there is a minimum associated breakage impulse required for maximum fragmentation to occur. This was also observed in other geometries, structures BWL2A and BWL2B, which share the same $1 \mathrm{~m} \times 1 \mathrm{~m}$ corner geometry, also develop the same basic crack patterns along the corner joints, yet BWL2A which was subjected to $110 \mathrm{kPa}$ shows a much higher number of initial fragments.

The similarities in crack formation are also apparent when comparing individual panels within the overall geometry. Structure BWL1B, which had a $2 \mathrm{~m}$ wide front panel and a $1 \mathrm{~m}$ side panel, is a supposition of structures BWL2B and BWL2C. At both 50ms and 150ms, the breakage of the corner section of BWL1B shows similar crack formation to BWL2B and the outside panel of BWL1B also shows the same initial crack pattern as BWL2C. Although the larger structure, BWL1B, showed the same basic crack pattern in each panel, the overall number of initial fragments was much higher. Structure BWL3B, a $2 \mathrm{~m}$ wide panel, shares 

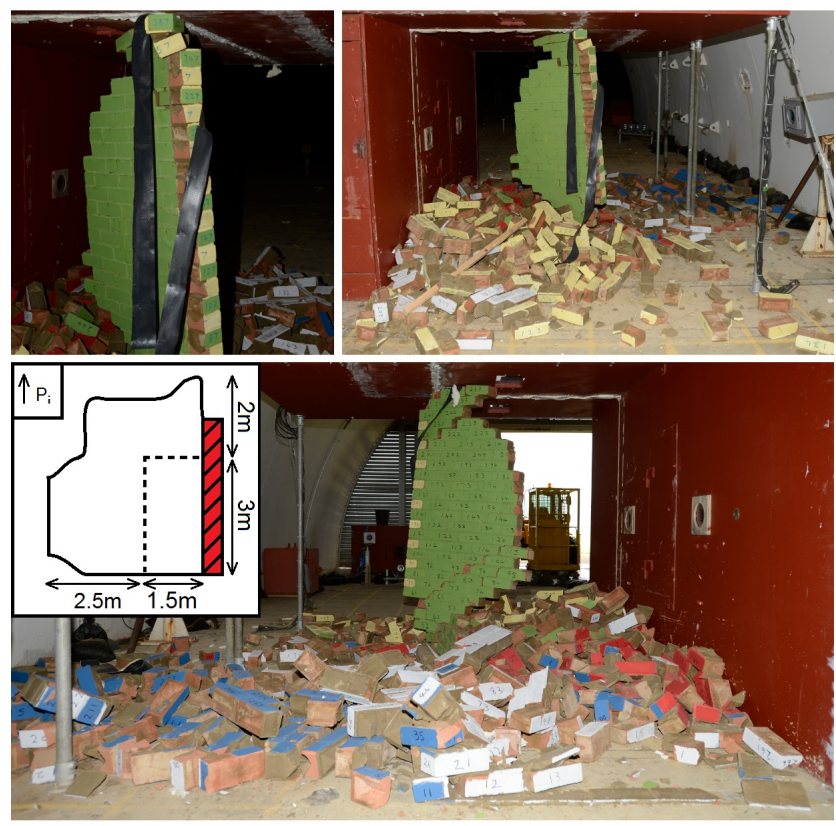

Figure 23: Debris distribution of structure BWL3C

the geometry of two BWL2C panels. The left, green panel of BWL3B shows very similar breakage as BWL2C at 50ms with two horizontal cracks dividing the structure into three approximately equal sized fragments. The right, red panel also forms horizontal cracks; however in slightly different positions, connected at the centre of the structure by stepped cracks. In both comparisons the overall breakage pattern is very similar; however the structure with the larger incident surface area develops more initial fragments.

The same basic patterns in the debris distribution occur based on the geometry of the structure. Every structure which had both front and side panels show the side panels forced outwards, followed by the front panel entrained in the blast wave with the farthest fragment always originating from the top three layers of the front panel. In the $4.9 \mathrm{~m}$ section of the ABT, the maximum longitudinal throw distance ranges from $42-50 \mathrm{~m}$, a difference of $16 \%$ and $12-14 \mathrm{~m}$ in the $10.2 \mathrm{~m}$ section, a difference of $15 \%$.

The debris distributions of the large enclosed structures all followed the same basic breakage patterns, differing only slightly with geometry. This led to all three debris distributions comprising the same basic shape, with slight differences resulting from the breakage pattern and thus geometry. Comparing the front panels of the enclosed structures with the unenclosed structures shows the additional fragmentation caused by drag and clearing effects. All of the large enclosed structures show minimal breakage on the front panel close to the steel enclosure, with each one developing only one low horizontal crack. In the absence of the steel wall, the clearing of the outer edge causes additional breakage on the unenclosed structures. The 
rear panels of the enclosed structures, which are shielded from infill, reduce the longitudinal distribution by absorbing the momentum of the front panels. In the absence of the steel enclosure, the blast infill from above is expected to cause failure in the rear panels and an outwards force on the side panels; without a rear wall absorb the momentum of the front panels, in combination with an equalised force on the side panels, a much larger longitudinal and lateral distribution is expected.

The initial crack lines and fractures formed within the first $25 \mathrm{~ms}$ greatly influence the initial fragmentation and the overall debris distribution. Cracking forms along the weakest parts of the structure and each test showed the cracks forming almost exclusively along bedding planes, with a total of $89 \%$ of bricks from all unenclosed structures remaining intact after testing. Breakage patterns can also be influenced by inherent weaknesses or inconsistencies within the structures; although this did not have too much of an effect within these experimental trials as similar structures follow similar failure mechanisms. A numerical modelling platform is currently under development to run a thorough analysis of the blast structure interactions, failure mechanisms and debris distribution patterns of each structure. The numerical modelling platform will then be used to expand the data set and aid in the development of simple predictive tools such as iso-damage curves for masonry debris.

\section{Acknowledgements}

Funding for analytical research provided by EPSRC Grant: EP/M009254/1. The authors would like to express gratitude to the UK Ministry of Defence for providing the use of testing facilities at MoD Shoeburyness. All data hereby obtained through the use of such facilities remains the property of the UK MoD. The assistance of the Spurpark Ltd trials division is gratefully acknowledged with respect to experimental planning, instrumentation and implementation.

\section{References}

[1] C. Needham, Blast Waves, Springer, 2010.

[2] G. H. Reid, Misty castle series: Mill race event: Test execution report, Tech. rep., Defence Nuclear Agency (1981).

[3] D. Eardley, J. Katz, Direct course and dust experiments, Tech. rep., Mitre Corp (April 1983).

[4] Steel Construction Institute, Buncefield explosion mechanism phase 1, Tech. rep., Steel Construction Institute (2009).

[5] Chemical Safety Board, Preliminary findings into the west fertilizer explosion and fire, Tech. rep., Chemical Safety Board (June 2013).

[6] G. S. Urgessa, K. Maji, Dynamic response for retrofitted masonry walls for blast loading, Journal of Engineering Mechanics.

[7] C. Mayrhofer, Reinforced masonry walls under blast loading, International Journal of Mechanical Sciences 44 (6) (2002) 1067 - 1080, seventh International Symposium on Structural Failure and Plasticity. 
[8] B. M. Abou-Zeid, W. W. El-Dakhakhni, A. G. Razaqpur, S. Foo, Response of arching unreinforced concrete masonry walls to blast loading, Journal of Structural Engineering 137 (2011) 1205 - 1214.

[9] X. Wei, M. G. Stewart, Model validation and parametric dtudy on the blast response of unreinforced brick masonry walls, International Journal of Impact Engineering 37 (11) (2010) 1150 - 1159.

[10] A. A. Mutalib, M. Abedini, S. Baharom, H. Hao, Deivation of empirical formulae to predict pressure and impulse asymptotes for p-i diagrams of one-way rc panels, Journal of Civil, Environmental, Structural, Construction and Architectural Engineering 7 (8) (2013) $585-588$.

[11] van der Voort, J. Weeheijm, A statistical description of explosion produced debris dispersion, International Journal of Impact Engineering 59 (2013) $29-37$.

[12] C. Knock, I. Horsfall, S. M. Champion, I. C. Harrod, The bounce and roll of masonry debris, The International Journal of Impact Engineering 30 (2004) $1-16$.

[13] A. Doerr, N. Gebbeken, M. Larcher, M. Steyerer, C. Haberacker, The effect of near-field explosions on masonry walls, in: 15th International Symposium on the Interactions and Effects of Munitions and Structures (15th ISIEMS), Potsdam, Germany, 2013, pp. P043, 1-12.

[14] S. Glasstone, P. J. Dolan, The Effect of Nuclear Weapons, United States Department of Defence, 1977.

[15] L. J. Adams, T. A. Rose, Simulating explosive events in the air blast tunnel, in: 22nd International Symposium on Military Aaspects of Blast and Shock, Bourges, France, 2012, pp. P58, 1-14.

[16] S. K. Clubley, Long duration blast loading of cylindrical shell structures with variable fill level, Thin Structures 85 (2014) $234-239$.

[17] C. N. Kingery, G. Bulmash, Airblast parameters from tnt spherical air burst and hemispherical surface burst, Tech. rep., U.S. Army Armament Research and Development Center, Ballistic Research Laboratory, Maryland (1984).

[18] The British Standards Institution, BS5628-1:2005 - Code of Practice for the use of Masonry, table 1, page 11 (2005).

[19] R. A. Keys, S. K. Clubley, Modelling debris distribution of masonry panels subject to blast loads using experimental \& applied element methods, in: 15th International Symposium on Interaction of the Effects of Munitions with Structures, Potsdam, Germany, 2013, pp. P069, 1-10.

[20] R. A. Keys, S. K. Clubley, Experimental analysis of small masonry panels subject to long duration blast loading, in: 16th International Symposium on Interaction of the Effects of Munitions with Structures, Sandestin, Florida, 2015 , pp. 1-7. 